\title{
Effect of Emotional Intelligence Training Program on Burnout among Psychiatric Mental Health Nurses
}

\section{Salwa Samy Sayed Ahmed ${ }^{1}$, Mona Hassan Abd El Aal ${ }^{2}$, Amal Ebrahim Sabra ${ }^{3}$ and Mona Mohamed Barakat ${ }^{4}$}

(1) Master degree in Psychiatric and Mental Health Nursing, Ain Shams University, Egypt (2) Professor of Psychiatric and Mental Health Nursing, the British University, Egypt (3) Assistant Professor of Psychiatric and Mental Health Nursing, Tanta University, Egypt (4) Assistant Professor of Psychiatric and Mental Health Nursing, Benha University, Egypt

\section{Abstract}

Background: Developing Emotional Intelligence in nurses increase psychiatric nurses stress resistance and combat burnout which become an essential element in nursing practice generally and psychiatric nursing practice more specifically. Aim of study: Was to evaluate the effect of EI training program on burnout among psychiatric mental health nurses. Research design: A quasi-experimental design one group was utilized. Setting: The study was conducted at the Psychiatric Mental Health Hospital in Benha City, Kaluobia Governorate, which is affiliated to General Secretariat of Mental Health. Sample: A convenient sample was constituted the study subjects, the sample size was 60 nurses, which carry out (pre/post/ and follow up test). Tools of data collection: Three tools were used I: A structured interviewing questionnaire consisting of 3 parts: Socio-demographic data, professional data and perception data. II: Emotional intelligence scale to assess the level of emotional intelligence of nurses and III: Maslash Burnout Inventory to assess the level of burnout among nurses. Results: There was a highly statistically significant difference of mean scores of emotional intelligence and burnout at post and follow up program comparing to pre- program implementation also, there was a statistically important negative association between emotional intelligence scores and burnout among psychiatric nurses. Conclusion: Emotional intelligence training program has positive effect on decreasing burnout among psychiatric mental health nurses. Recommendations: Continuous emotional intelligence education courses involved in the workplace to develop skills of nurses to decrease burnout among the staff.

Key words: Burnout, Emotional intelligence, Psychiatric nurses, Training program.

\section{Introduction}

The healthcare system has been widely acknowledged to be a stressful system with manpower shortage and high demands. Compared to other healthcare professionals, nurse shaves the highest level of stress and burnout. This is because other healthcare professionals such as doctors and therapists spend limited amounts of time with patients. This is associated with feelings of hopelessness, difficulties in dealing with work and doing one's job effectively. Although closely related, stress and comparatively, nurses are the first line of contact; they spend the most time with patients and are constantly exposed to the emotional strains of dealing with the sick and death (Chanu \& Shiroor, 2019).

Job burnout is a situation that results from repeated exposure such stressors when left neglected lead to burnout to instances of work-related stress characterized by known 
physical, emotive and mental exhaustion. Burnout is a psychological term described the experience of long-term exhaustion, frustration, anger and depression. Burnout is not synonymous. Negative consequences of burnout include drug and alcohol misuse, marital and family conflicts. Psychiatric consequences include depression, anxiety disorders and even suicide. It can also lead to increased incidence of clinical errors, patient dissatisfaction and staff turnover. Furthermore nurses experiencing burnout can feel frustrated, tired, disinterested in work and a dip in productivity, leading to illness, interpersonal conflict and emotional suffering (Ribeiro et al., 2019).

Psychiatric \& mental health nurses with high emotional intelligence should be capable of managing emotional stressors and as a result are more likely to experience less burnout and can protect them from the negative effects of workplace stressors and improve social skills, leading to long-term benefits in occupational health. Emotionally intelligent nurses will be better equipped to derive meaning, interpret and act appropriately in dealing with emotions and that of others when being faced with emotionally charged situations (Ong, 2017).

The emotional intelligence training program helps the psychiatric nurse to have a good positive attitude, better relationships and increase adaptability. Higher emotional intelligence is important to satisfy the needs of the patient-centered care in nursing, increasing emotional intelligence not only benefits the patients, also nurses stand to benefit in several ways. Studies found that a greater level of emotional intelligence connected with reduced stress and burnout so, this study was aimed to evaluate the effect of emotional intelligence training program on burnout among psychiatric mental health nurses (Foji et al., 2020).
Significance of the study

Psychiatric nursing is a profession with specific responsibilities and opportunities\& existing literature has demonstrated that mental health nurses are experiencing high levels of stress and burnout. Burnout is a psychological syndrome defined as a state of psychological, emotional, and physical stress in response to prolonged exposure to occupational stress (Dewa et al., 2017).

Emotional intelligence training has been proposed as a promising intervention for reducing stress and burnout in healthcare professionals. Psychiatric nurse with high levels of emotional intelligence show more job satisfaction, and perform more successfully in relation to patients, and undergo less occupational burnout. High emotional intelligence psychiatric mental health nurses will be able to emancipate patients in a way they can understand patient's feelings. In the same time, help the patient to develop self-awareness, liability, and approach own strengths and supports (Hunt et al., 2017).

Hence this study will improve the efforts to alleviate professional burnout and raise the standard of occupational welfare of nurses in workplace through implementation of emotional intelligence training program.

\section{Aim of the study:}

The study aimed to evaluate the effect of emotional intelligence training program on burnout among psychiatric mental health nurses.

\section{Research hypothesis:}

Burnout among psychiatric mental health nurses was expected to be decreased after implementation of the emotional intelligence training program. 


\section{Subject and Methods}

\section{Research design:}

A quasi-experimental design one group was utilized to fulfill the aim of the study.

\section{Study setting:}

The study was conducted at the Psychiatric Mental Health Hospital in Benha City, Qalubia Governorate, which is affiliated to General Secretariat. It has 7 departments (4 men department, 1 female department, Emergency department and addiction department) with capacity of 219 beds serving the patient with psychiatric and mental disorder. The total nursing number is 225 nurses, the nurses who working closely to patient care was 110 nurses.

\section{Sample:}

a- Sample type: A convenient sample was constituted the study subjects.

b- Sample size: 60 nurses, one study group who carry out (pre/post/ and follow up test)

Tools for data collection:

Three tools were used for data collection:

\section{Tool (1): Structured Interview Questionnaire which consisted of 3 parts:-}

Part one: Socio-demographic data: It contained questions about characteristics of the studied nurses (age, sex, level of education, marital status and occupation).

Part two: Professional data: It included (years of experience in nursing as general and years of experience in psychiatric hospital, received training on Emotional Intelligence (EI), work shift \& monthly salary)

Part three: Perception data: It included (incentive, nature of work and intention to leave the psychiatric hospital)
Tool II: - Emotional Intelligence Scale: It developed by Schutte et al., (1998), it used to measure emotional intelligence by using a self-administered questionnaire. It consisted of 33 items. The response to each item is given based on a 3 Lickert scale (always) 1, (sometimes) 2 and (rarely) 3. The total score of the items is from 33 to 99 for reversed questions $(5,28$, and 33$)$ the scoring is reversed.

\section{Scoring system:}

- Low level of EI: 33 - 54 score.

- Moderate level of EI: 55 - 76 score.

- High level of EI: 77 - 99 score.

Tool III: Maslash Burnout Inventory (MBI): It designed by Maslach and Jackson, (1981) to assess the level of burnout among nurses. It is a selfadministered 7 Likert-type questionnaire with 22 statements that divided into three dimensions of burnout: Emotional Exhaustion (EE), Depersonalization (DP), Personal accomplishment (PA). The MBI is scored on a 7-point scale from never (0) to everyday (6) and Results are calculated for each of the subscales separately

\section{Scoring system:}

\section{Emotional Exhaustion:}

- High: 27or over.

- Moderate: 17-26

- Low: 0-16

\section{Depersonalization:}

- High: 13 or over

- Moderate: 7-12

- Low: 0-6

Personal Accomplishment:

- High : 39 to over

- Moderate: 32-38

- Low: 0-31

Total level of burnout:

- Low: 59 to less

- Moderate: 46-76

- High: 79 and above 


\section{Tools validity and reliability}

The validity of tools had done through five expertise professors of Psychiatric \& mental Health Nursing Specialties, from different Nursing Faculties. All tools for data collection were tested for its reliability using test retest reliability and all tools (emotional intelligence scale and Maslach burnout inventory) were proved to be strongly reliable. This was done using the assessment of their internal consistency. The reliability proved to be high ( $\mathrm{r} .=0.79$ and $0.69)$ respectively.

\section{Pilot study}

A pilot study was carried out on 30 $\%$ to ensure the clarity, applicability and feasibility of the study tools.

\section{Ethical considerations}

The psychiatric nurses were briefed about the purpose of the study, encouraged and give fully informed verbal con-sent to participate. It was emphasized that all data collected was strictly confidential and the data would be used for scientific purposes only and she has full right to withdraw from the study at any time.

\section{Field work:}

The data collection took about 9 months from April 2020 to December 2020. The training program was carried out in the nursing room of study setting on small group basis. This room not specified for training but, because of Covid 19 pandemic crises, the training room was closed for any training and meeting.

Pre assessment phase: A comfortable, private place was chosen for the interviewers. Orientation was done about the researcher's name, purpose, significance, content of the study. Subjects were interviewed where preassessment was done using (1) Structured Interviewing Questionnaire, and Schutte emotional intelligence questionnaire (EIQ). Implementation phase: This study hypothesized that burnout among the psychiatric nurses will be reduced after attending emotional intelligence training program than before program. This training program has a general objective and divided into session each session has a set of specific objectives. This was achieved through several teaching methods such: brain storming, lecture, discussion, providing the example. Data show, video, role play and pictures were used as media. Communication skills, assertiveness skills, responding to criticism skills, role played and video graphed. At the end of each session summary, feedback, further clarifications were done for vague items and homework for the next session.

The content of the intervention program sessions was as follows: The nurses were enrolled for 10 sessions, each lasting for 45 to 90 minute, on a daily basis. Based on the results obtained from the assessment tools and review of literature, the program content was developed by the researcher in the form of a booklet, which was distributed for nurses in the first session. Sessions of emotional intelligence program focused on:

The $1^{\text {st }}$ session: Introduction about aim, objectives and content of the sessions. The $2^{\text {nd }}$ session: Theoretical background about psychiatric nursing \& burnout

The $3^{\text {rd }}$ session: Theoretical background about emotional intelligence

The $4^{\text {th }}$ session: developing Self-awareness. The $5^{\text {th }}$ session: developing self-regulation. The $6^{\text {th }}$ session: developing self-motivation of the nurses.

The $7^{\text {th }}$ session: understanding and developing Empathy skills.

The $\mathbf{8}^{\text {th }}$ session: improving social skills training. 
The $9^{\text {th }}$ session: Practical steps to increase social skills

The10 ${ }^{\text {th }}$ session: Summary about the program sessions and post-assessment test.

After each session the researcher revised the homework and give feedback about the previous session.

\section{Evaluation design:}

After program implementation the post test was carried out to assess (emotional intelligence skills and level of burnout) by using the same tools of the pretest. This helped to evaluate the effect of implemented program. This was done twice one; immediately after the intervention and implementation of the training program, and follow up was implemented after 3 months of completion the program.

\section{Statistical analysis:}

All data were collected, coded, tabulated and subjected to statistical analysis. Statistical analysis was performed by statistical Package for Social Sciences (SPSS version 20.0). Descriptive statistics were applied in the form of mean and standard deviation for quantitative variables and frequency and percentages for qualitative variables. Qualitative categorical variables were compared using chi-square test. Statistical significance was considered at $\mathrm{p}$-value $\mathrm{p} \leq 0.05$, and considered highly statistically significance at $\mathrm{p}$-value $\mathrm{p} \leq$ 0.001 .

\section{Results:}

Table (1): Reveals that more than half (56.7\%) nurses were female with a mean age $(42.15 \pm 8.03)$. Also, in relation to marital status the majority of them $(90 \%)$ were married. Regarding their educational level more than half $(61.7 \%)$ of them had diploma in nursing but only half of them $(51.7 \%)$ were nursing staff.

Table (2): Reveals that nearly two thirds had 15 years or more at both nursing and psychiatric field. Also, more than one third (38.3\%) had work 24 hours per-shift. While all studied nurses $(100 \%)$ had not attend courses about emotional intelligence yet

Table (3): Shows the perception of the studied nurses regarding work. The results revealed that slightly less than half (48.3\%) considered nature of work was hard. Also, less than half (40\%) had sufficient monthly salary. Regarding their incentive more than half $53.3 \%$ of studied nurses considered the incentive suitable with work hazard.

Figure (1): Illustrates distribution of the studied nurses regarding level of emotional intelligence. at pre-program implementation more than four fifth $(85 \%)$ of the studied nurses were moderate level compared (10\%) at post implementation of the program and $0 \%$ at follow up implementation of the program.

Figure (2): Illustrates distribution of the studied nurses regarding level of burnout. at pre implementation of the program four fifth of the study sample (80\%) were high level of burnout compared to $0 \%$ were high level of burnout at post implementation of the program and $5 \%$ at follow up implementation of the program

Table (4): Reveals that there was negative correlation between depersonalization and emotional intelligence scores at pre implementation of the program. Furthermore, there was negative correlation between emotional intelligence scores and dimensions of burnout (emotional exhaustion and depersonalization) at post 
and follow-up; lastly, there was a highly statistically significant positive correlation between emotional intelligence scores and personal accomplishment at post and follow up implementation of the program

Table (5): Shows that there was a significant statistical negative correlation between emotional intelligence score and level of burnout at pre implementation of the program, while there was a highly statistically significant negative correlation between emotional intelligence score and level of burnout at post implementation of the program at $\mathrm{P}$-value $=<0.000$. Also, there was statistically significant negative correlation between emotional intelligence score and level of burnout at follow up implementation of the program at P-value $=<0.005$.

Table (1): Socio-demographic of the studied nurses $(n=60)$ :

\begin{tabular}{|c|c|c|}
\hline Socio-demographic characteristics & $\mathbf{N}$ & $\%$ \\
\hline \multicolumn{3}{|l|}{ Age (years) } \\
\hline $25-<35$ years & 10 & 16.7 \\
\hline $35-<45$ years & 23 & 38.3 \\
\hline$\geq 45$ years & 27 & 445.0 \\
\hline Mean \pm SD & \multicolumn{2}{|c|}{$42.15 \pm 8.03$} \\
\hline \multicolumn{3}{|l|}{$\overline{\text { Sex }}$} \\
\hline Male & 26 & 43.3 \\
\hline Female & 34 & 56.7 \\
\hline \multicolumn{3}{|l|}{ Marital status: } \\
\hline Single & 2 & 3.3 \\
\hline Married & 54 & 90.0 \\
\hline Divorced & 1 & 1.7 \\
\hline Widow & 3 & $\overline{5.0}$ \\
\hline \multicolumn{3}{|l|}{ Educational level } \\
\hline Nursing diploma & 37 & 61.7 \\
\hline $\begin{array}{l}\text { Nursing association (technical } \\
\text { institute) degree }\end{array}$ & 8 & 13.3 \\
\hline Bachelor in nursing & 15 & 25.0 \\
\hline \multicolumn{3}{|l|}{ Occupation } \\
\hline Staff nurse & 39 & 65.0 \\
\hline Nurse specialist & 9 & 15.0 \\
\hline Nurse supervisor & 12 & 20.0 \\
\hline
\end{tabular}


Table (2): Distribution of the studied nurses according to their professional characteristics $(\mathbf{n}=60)$

\begin{tabular}{|c|c|c|}
\hline Professional characteristics & $\mathbf{N}(\mathbf{n}=60)$ & $\%$ \\
\hline \multicolumn{3}{|c|}{ Years of experience in nursing field } \\
\hline $5-<10$ years & 10 & 16.7 \\
\hline $10-<15$ years & 11 & 18.3 \\
\hline 15 years or more & 39 & 65.0 \\
\hline Mean \pm SD & \multicolumn{2}{|c|}{$15.5 \pm 4.47$} \\
\hline \multicolumn{3}{|c|}{ Years of experience in psychiatric nursing field } \\
\hline $2-<5$ years & 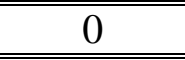 & 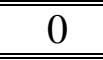 \\
\hline $5-<10$ years & 10 & 16.7 \\
\hline $10-<15$ years & 11 & 18.3 \\
\hline 15 years or more & 39 & 65.0 \\
\hline Mean \pm SD & \multicolumn{2}{|c|}{$15.5 \pm 4.47$} \\
\hline \multicolumn{3}{|l|}{ Work shift } \\
\hline Morning shift only & 7 & 11.7 \\
\hline 24 hour shift & 23 & 38.3 \\
\hline 12 hour day & 15 & 25.0 \\
\hline 12 hour night & 15 & 25.0 \\
\hline \multicolumn{3}{|c|}{ Did you attend course about Emotional Intelligence } \\
\hline No & 60 & 100.0 \\
\hline
\end{tabular}

Table (3): distribution of the studied nurses according to their Perception about work among the studied nurses $(\mathrm{n}=60)$.

\begin{tabular}{|c|c|c|}
\hline Item & $\mathbf{N}(\mathbf{n}=60)$ & $\%$ \\
\hline \multicolumn{3}{|l|}{ Nature of work } \\
\hline Hard & 29 & $\overline{48.3}$ \\
\hline Somewhat hard & 21 & 35 \\
\hline Not hard & 10 & 16.7 \\
\hline \multicolumn{3}{|l|}{ Monthly salary } \\
\hline Sufficient & 24 & 40 \\
\hline To some extent & 16 & 26.7 \\
\hline Insufficient & 20 & 33.3 \\
\hline \multicolumn{3}{|l|}{ Incentive } \\
\hline $\begin{array}{l}\text { Suitable with work } \\
\text { hazard }\end{array}$ & 32 & 53.3 \\
\hline $\begin{array}{l}\text { Not suitable with work } \\
\text { hazard }\end{array}$ & 28 & 46.7 \\
\hline \multicolumn{3}{|c|}{ Do you think to leave the psychiatric hospital } \\
\hline Yes & 7 & 11.7 \\
\hline No & 53 & 88.3 \\
\hline
\end{tabular}




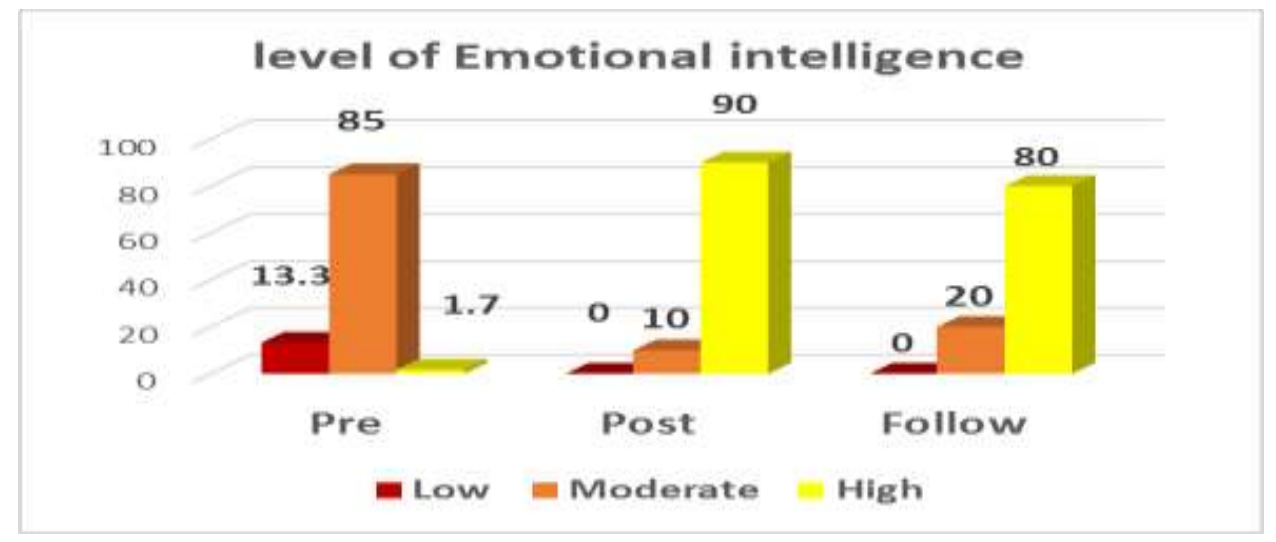

Figure (1): Distribution of the studied nurses regarding to their levels of emotional intelligence $(n=60)$.

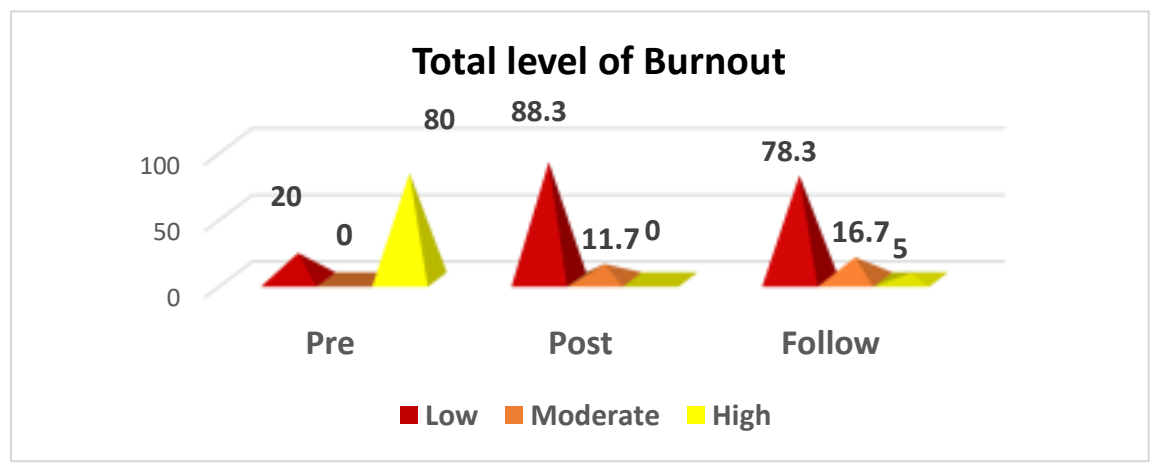

Figure (2): Distribution of the studied nurses regarding to their level of burnout $(n=60)$.

Table (4): Correlation between total emotional intelligence burnout dimensions of the studied nurses at pre, post and follow up implementation program $(\mathbf{n}=60)$.

\begin{tabular}{|c|c|c|c|c||}
\hline \multicolumn{2}{||c||}{ Burnout dimension } & $\begin{array}{c}\text { Emotional } \\
\text { intelligence } \\
\text { (Pre) }\end{array}$ & $\begin{array}{c}\text { Emotional } \\
\text { intelligence } \\
\text { (Post) }\end{array}$ & $\begin{array}{c}\text { Emotional } \\
\text { intelligence } \\
\text { (follow) }\end{array}$ \\
\hline \multirow{2}{*}{$\begin{array}{c}\text { Emotional } \\
\text { exhaustion }\end{array}$} & $\mathrm{R}$ & -0.20 & $-0.65^{* *}$ & $-0.91^{* *}$ \\
\cline { 2 - 3 } Depersonalization & $\mathrm{P}$ & 0.12 & 0.000 & 0.000 \\
\cline { 2 - 5 } & $\mathrm{R}$ & $-0.97^{* *}$ & $-0.73^{* *}$ & $-0.59^{* *}$ \\
\hline \hline \multirow{2}{*}{$\begin{array}{c}\text { Personal } \\
\text { accomplishment }\end{array}$} & $\mathrm{P}$ & 0.004 & 0.000 & 0.009 \\
\cline { 2 - 5 } & $\mathrm{P}$ & 0.23 & $0.81^{* *}$ & $0.83^{* *}$ \\
\hline \hline
\end{tabular}


Table (5): Correlation between total burnout and total emotional intelligence of the studied nurses pre, post and follow up implementation program $(n=60)$.

\begin{tabular}{|c|c|c|c|}
\hline \multirow{2}{*}{\multicolumn{2}{|c|}{ Scales }} & \multicolumn{2}{|c|}{$\begin{array}{c}\text { Total emotional } \\
\text { intelligence scale }\end{array}$} \\
\hline & & 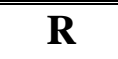 & p-value \\
\hline \multirow{3}{*}{$\begin{array}{c}\text { Total burnout } \\
\text { scale }\end{array}$} & Pre program & -0.36 & $0.03 *$ \\
\hline & Post program & -0.39 & $0.002 * *$ \\
\hline & Follow up program & -0.70 & $0.005^{*}$ \\
\hline
\end{tabular}

\section{Discussion:}

Emotional intelligence acts as a vital element in shaping the reactions of an individual towards external stimuli. High emotional intelligence among psychiatric mental health nurses will enabled them to emancipate those patients in a way they can understand patient's feelings. In the same time, help the patients to develop selfawareness, liability, and approach their own strengths and supports. Psychiatric mental health nurses with high emotional intelligence are able to encounter patient's weaknesses and fears and to provide high standard of care. Therefore, the emotional intelligence training program for psychiatric mental health nursing is very important in helping nurses dealing with stress and burnout and promotes mental health of the nurses (Aldossary, 2019). So that, this study was aimed to evaluate the effect of emotional intelligence training program on burnout among psychiatric mental health nurses.

Concerning to the personal characteristics of the studied nurses, the present study revealed that the mean age of the studied nurse was $42.15 \pm 8.03$. It could be due to less than half of the studied nurses their age's more than 45 years and constitute the more percentage in the study.
This finding is disagree with the study by Zaki \&Barakat, (2018) stated that more than half of them their age are between $20-<35$ years with a mean age of $33.437 \pm 8.001$ years.

In relation to their sex, the present study showed that more than half of the studied nurses were female. It might due to the female nurses consider this profession is more suitable for them to help themselves and their families in financial support. This result was in agreement with the finding of the study by Zaki, (2016) clarified that females are relatively more common as main worker constituting more than two- third of psychiatric nurses under the study.

Regarding to their marital status, the present study noticed that the majority of the studied nurses were married. It could be due to their ages above 45 years, so the most of them definitely married. This result was in line with the study by Habadi, (2018) stated that more than three quarter of the studied nurses were married.

Concerning to the educational level, the present study revealed that more than half of the studied nurses had diploma secondary school. It may be due to as a result of their ages the most of them stop their educational level at diploma secondary school and didn't 
continue their education. This result was disagreement with the study by Hussein \&Mohamed, (2020) stated that the highest percentages of participants were nurse specialists. Meanwhile, one fifth of them were nurses and one third of study sample were technical nurses.

Regarding the occupation of the studied nurses, the present study demonstrated that slightly less than two third of the studied nurses were staff nurse. It might be due to that the dominant educational level of the study sample was diploma secondary school; so that, they work as staff nurses. This finding was in agreement with the study by Rakhshani et al., (2018) stated that the majority of them were ordinary staff.

In relation to years of experience of the studied nurses, the present study showed that less than two third of the studied nurses their experience more than 15 years in general and psychiatric nursing field respectively. It could be due to the mean age of the studied nurses $42.15 \pm 8.03$ so that, higher nurses ages mean more years of experience in nursing work. This finding is incontrast with the study by Hassan et al., (2019) stated that more than one-third of the studied sample had from (5 10) years' of experience.

Concerning to work shift, the present study revealed that more than one third of nurses take 24 hours shift and one quarter of them attending 12 hours day shift and night shift respectively. It could be due to the nature of the pandemic problem of Corona virus that obliged the country to imposed curfew so that, the nurses prefers to take 24 hours come at day and back to their home next day. This finding is incontrast with Ali, (2015) stated that about $8 \%$ of the studied nurses take night shift.
In relation to monthly salary, the present study showed that less than half of the studied nurses consider their salary sufficient to them. It could be due to the psychiatric and mental health hospitals that affiliated to general secreterate their salaries considered high than the other general hospitals. This study was inconsistent with the study by Habadi, (2018) stated that slightly less than two third were satisfactory with their income

Concerning to attending courses about EI, the present study showed that the all study sample have not attend any courses about the EI. It could be due to the training program in the hospital contain only nursing lecture that related to their work not training that help them to improving their skills. The result is agreement with the study by Zaki et al., (2018) stated that the majority of the study nurses didn't attend courses about EI.

In relation to nature of work, the present study conducted that less than half of the studied nurses believed that their work is hard to them. It could be due to the psychiatric environment has some sort of violence from aggressive patients and difficulties in dealing with mental ill patient that may affect the nursing staff and need more appreciation from the organization.

Concerning to the incentives, the present result revealed that more than half of the studied nurses believed their incentive is suitable with work hazard. It could be due to the psychiatric and mental health hospital having special incentives compared to the general hospitals.

The present study stated that more than four fifth of studied nurses not thinking to leave the psychiatric hospital. It could be due to the difficulty of transferring to another hospital especially not psychiatric hospital. 
In relation to the emotional intelligence scores, the present study revealed that the majority of the studied nurses have high level of emotional intelligence at post implementation of the program and declined to four fifth at follow up the program compared to pre-program. From the researcher point of view it may be due to effective emotional intelligence program for improvement and enhancement of the emotional intelligence skills that resulting in increasing the high level of the emotional intelligence after training program.

Concerning to the total level of burnout of the studied nurses, the present study illustrated that the majority of the studied nurses have high level of burnout pre-program and decrease at post and follow up of the program. This improvement of the total level of burnout may be due to the effectiveness of the emotional intelligence training program on decreasing the level of emotional exhaustion, depersonalization and increased the level of personal accomplishment which subsequently decreased the total level of burnout among the studied nurses.

The present study illustrated that, there was a highly statistically significant negative correlation between emotional exhaustion\& emotional intelligence subscales at post implementation of the program. It could be due to that the emotional exhaustion is the depleted of one's emotional and physical resources that lead the studied nurses to feel drained and used up but with increasing their emotional intelligence skills and developing their abilities to control over their anger and stress and applying the relaxation technique that benefit them to evacuate their negative energy and chronic stress. Furthermore, the studied nurse become less exhausted and able to feel energy and faces the day work problems and decreased their emotional burned from their profession.

The present study showed that, there was a highly statistically significant negative correlation between depersonalization\& emotional intelligence subscales at post implementation of the program. It may be due to the depersonalization developed in response to overload of emotional exhaustion, that affect the nurses and caused them to put distance between them and their patients and considering them impersonal object of their work, while after implementation of the training program and developing their empathy, utilization of their emotion and their social and communication skills, so that the studied nurses depersonalization decreased with increasing the emotional intelligence skills after post program implementation.

The present study showed that, there was a highly statistically significant positive correlation between emotional exhaustion\& emotional intelligence subscales at post implementation of the program. It may be due to reduced personal accomplishment means lack of achievement, productivity and feeling incompetence at work that improved and increased with increasing emotional intelligence training program that enhanced the self-awareness of the studied nurses and motivated themselves that making them aware of their strength and weakness points that helped them to achieved growth and dealing well with difficult situation at work.

This result is in line with the study by Năstasă et al., (2015) indicated that personal accomplishment in healthcare professionals is influenced by the level of emotional intelligence development and they support the importance of a training focused on developing emotional intelligence in specialists from the healthcare system.

The findings are matched with the study by Barkley, (2013) conducted that there was 
a significant and inverse relationship between emotional intelligence and burnout. Furthermore, for the dimensions of burnout and total emotional intelligence, there was a significant and inverse relationship between emotional intelligence and emotional exhaustion, as well as a statistically significant and inverse correlation between emotional intelligence and depersonalization. Moreover, a significant and direct correlation was found between personal accomplishment and emotional intelligence.

The present study illustrated that there was a highly statistically significant negative correlation between depersonalization and emotional intelligence scores at pre implementation of the program. While there was no significant correlation between emotional intelligence scores and emotional exhaustion and personal accomplishment at pre-program implementation. Furthermore, there was a highly statistically significant negative correlation between emotional intelligence scores and dimensions of burnout (emotional exhaustion and depersonalization) at post and follow up implementation of the program. Lastly, there was a highly statistically significant positive correlation between emotional intelligence scores and personal accomplishment at post and follow up implementation of the program.

This result is in line with the study by Năstasă et al., (2015) stated that there is negative correlation between the level of emotional intelligence development and the burnout syndrome dimensions (emotional exhaustion, depersonalization and personal accomplishment), a medium to large statistically significant correlation between the development of emotional intelligence and personal accomplishment.

Furthermore, the present study showed that, there is a highly statistical significant negative correlation between total emotional intelligence scores and level of burnout at post implementation of the program. While there is a statistically significant negative correlation between emotional intelligence scores and burnout scores at pre and follow up implementation of the program. It could be due to the effectiveness of the training program in enhancing and increasing the emotional intelligence skills among psychiatric nurses that leads to alleviating the burnout level among them.

The finding is matched with the study of Gong et al., (2019) stated that improve nurses' EI level will effectively slow down or eliminate nurses job burnout. Also, the finding is congruent with the study of Tebani, (2017) showed the effectiveness of therapeutic program in the development of emotional intelligence skills and alleviating the burnout among the study subjects.

\section{Conclusion:}

The findings confirmed the effectiveness role of emotional intelligence training program (theoretical and practical) in decreasing the burnout level among the psychiatric mental health nurses after receiving emotional intelligence training program. There was highly statistically significant negative correlation between scores of emotional intelligence and scores of burnout among the study sample of the psychiatric mental health nurse at post implementation of the program. This conclusion leads to the acceptance of the study hypothesis that the emotional intelligence training program has decreases the burnout level among psychiatric mental health nurses.

\section{Recommendation:}

- Intervention programs are recommended for nurses to enhance their level of emotional 
intelligence skills to improve their coping ability, and to reduce their level of burnout.

- Training program should be included in nursing curriculum of Nursing educations, especially future PMHN.

- Nurses should be encouraged to reflectively examine their own level of EI and should be educated on how to express their negative emotion towards others.

\section{References:}

Aldossary, N. (2019). Study of Emotional Intelligence among Psychiatric Mental Health Nurses in Eastern Province, Saudi Arabia. IOSR Journal of Nursing and Health Science (IOSR-JNHS),vol. 8, no. 06, pp. 01-11.

Ali, M. (2015). Effect of Shift Work on Physical and Psychological Health of Nursing staff. Master thesis, psychiatric mental health nursing, Ain shams University.

Barkley, E. (2013). The relationship between emotional intelligence and burnout amongst social workers in the north and south regions of the western cape, minithesis, university of the western cape.

Chanu, N., Shiroor, G. (2019). Burnout among staff nurses working in hospitals The Pharma Innovation Journal; 8(6): 312-315.

Codier, E. \& Codier, D. (2015). Do emergency nurses have enough emotional intelligence. Emergency nurse 23 (3), 26-29.

USA: Art \&science.

Dewa, C., Loong, D., Bonato, S., \& Trojanowski, L. (2017). The relationship between physician burnout and quality of healthcare in terms of safety and acceptability: a systematic review. BMJ Open. 7(6):e015141.doi:10.1136/bmjopen2016-015141.

Foji, Vejdani , M., , Salehiniya, H., and Khosrorad, R. (2020). The effect of emotional intelligence training on general health promotion among nurse. Journal
Educ Health Promot, doi: 10.410 3/jehp.jeh p_134_19

Gong Z., Chen Y., and Wang $Y$. (2019). The Influence of Emotional Intelligence on Job Burnout and Job Performance: Mediating Effect of Psychological Capital, Front. Psychol. 10:2707.doi:10.3389/fpsyg.2019.02707

Habadi, A. (2018). The Prevalence of Burnout Syndrome among Nursing Staff Working at King Abdul-Aziz University Hospital, Jeddah, Saudi Arabia, Diversity and Equality in Health.

Hassan, S., Abdel-Aziz, H. and Mohamed, F. (2019). Work Related Stress, Burnout and Self-efficacy among Psychiatric Nurses International Journal of Novel Research in Healthcare and Nursing. Vol. 6, Issue 2, pp: (729-744), Month: May - Available at: $\begin{array}{llll}\text { www.noveltyjournals.com } & \text { Page } & 729\end{array}$ Novelty Journals.

Hussein, N., A. \& Mohamed, B., E. (2020). The Effect of Empathy-Based Training Program on Communication Skill and Burnout among Psychiatric Nurses". IOSR Journal of Nursing and Health Science (IOSR-JNHS), 9(1), pp. 43-55. DOI: 10.9790/1959-0901044355

www.iosrjournals.org 43.

Hunt, P., Denieffe, S.\& Gooney, M., (2017). Burnout and its relationship to empathy in nursing: a review of the literature. Journal of Research in Nursing. 22(1-2): 7-22.

Maslach, C. \& Jackson, S. (1981). The measurement of experienced burnout. Journal of occupational behavior, 2 , pp. 99113.

Năstasă, L. \& Cazan, A. (2015). Emotional intelligence, satisfaction with life and burnout among university students- Social and Behavioral Sciences 180 ,1574 - 1578 Available online at www.science direct. com1877-0428. 
Ong, W. (2017). The significance of emotional intelligence in nursing, https://today.mims.com/the significance-ofemotional intelligence-in-nursing 16/9/2019.

Rakhshani, T., Motlagh, Z., Beigi, V., Rahimkhanli, M. and Rashki, M. (2018). The relationship between emotional intelligence and job stress among nurses in Shiraz, Iran. Malays J Med Sci.;25 (6):100109, https://doi.o rg/10.21315/mj ms2018 .25.6.10 nd Care (2018) 15(3): 122-126.

Ribeiro, V., F., Filho, C., F., Valenti, V., E., Ferreira, M., de Abreu LC, de Carvalho TD. (2019). Prevalence of burnout syndrome in clinical nurses at a hospital of excellence. International archive of Medicine; 7:22 Available from: https://www. ncbi.nlm.nih .gov/pubmed $\underline{24860618}$

Schutte, N., Malouff, J., hall, l., haggerty, D., Cooper, J., Golden, C. \& Dornheim, I. (1998). Development and validation of a measure of emotional intelligence. Personality and Individual Differences, 25(2), 167-177.

Tebani, s. (2017). The effectiveness of a therapeutic program in the development of emotional intelligence and alleviation of psychological burnout in sample of doctors.

Zaki, M., M., \& Barakat, M., A., M. (2018). Effect of Stress Management on Job Related Stress Among Nurses Working with Psychiatric Patients, IOSR Journal of Nursing and Health Science (IOSR-JNHS) e-ISSN: 2320-1959.p-ISSN: 2320-1940 Volume 7, Issue 1 Ver. IV. (Jan.-Feb .2018), PP 22-30.

Zaki, R. (2016). Job Stress and SelfEfficacy among Psychiatric Nursing Working in Mental Health Hospitals at Cairo, Journal of Education and Practice.7 (20), Pp. 103 -113. 
تأثير البرنامج التدريبي عن الذكاء الوجدانى على الاحترلق النفسى لاى ممرضى الصحة النفسية والعقلية سلوى سامى سيدأحمد- منى حسن عبدالعالـ أمل ابر اهيم صبر ا- منى ححم بركات

التمريض النفسي هو مهنة ذات مسؤوليات ومجالات متخصصة وقد أظهرت الدراسات السابقة أن

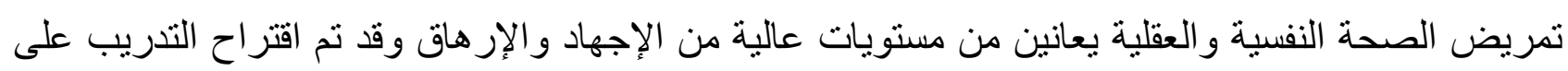

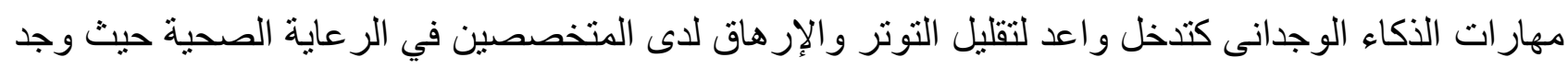

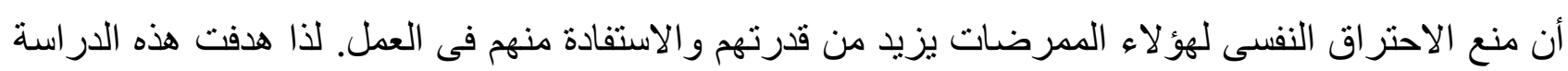

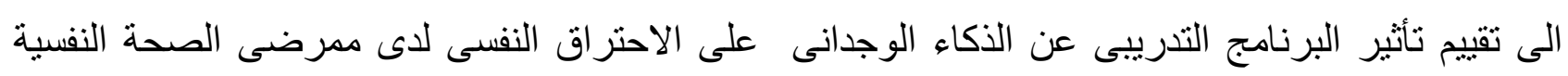

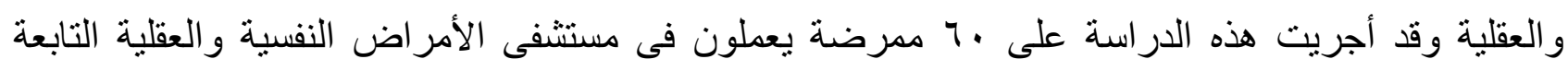

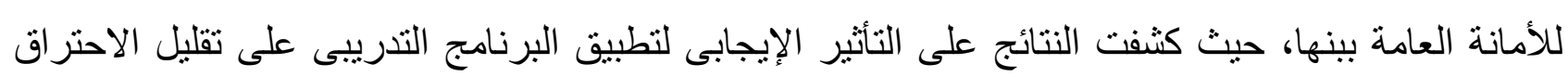

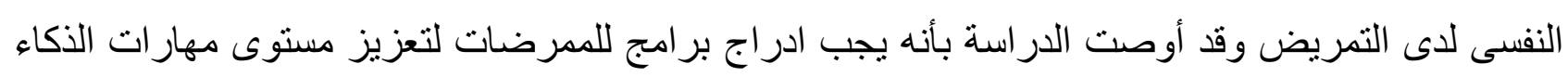
الوجدانى لديهم لتحسين قدرتهم على التأقلم ، وتقليل مستوى الإر هاق لديهر. 